\title{
El juego de las sillas, o la participación como redistribución de poder
}

Jaron Rowan | Unidad de Investigación y Doctorado de BAU, Centro Universitario de Diseño

URL de la contribución <www.iaph.es/revistaph/index.php/revistaph/article/view/4725>

Resulta interesante preguntarse si el ciclo político iniciado con el 15M en España y caracterizado por la llegada a las instituciones de partidos y organizaciones surgidas en el contexto de los movimientos sociales (o en espacios aledaños) ha dado pie a una verdadera transformación institucional. Si bien es verdad que las políticas culturales no han estado en el centro de los debates que han definido este proceso, constatamos que, en mayor o menor medida, ha habido intentos y planes de articulación de la cultura en las diferentes ciudades gobernadas por representantes de la denominada "nueva política" (BARBIERI, 2018). Muchos de los programas de quienes concurrieron a las elecciones legislativas del año 2015 estaban marcados por la llamada a la participación y, si revisamos con más detalle las propuestas de política cultural, notaremos que se repite la idea del impulso a una "cultura común". Con esto vemos que dos tipos de demandas diferentes acontecieron en paralelo y en ocasiones se han cruzado.

Se defiende la participación ya que constituye una herramienta de democratización institucional. Un Estado democrático avanzado es aquel capaz de otorgar un papel activo a la ciudadanía en la toma de decisiones sobre asuntos que le conciernen (ROSANVALLON, 2015). El Estado social ha de facilitar los mecanismos para escuchar y hacerse cargo de demandas y necesidades ciudadanas. La capacidad de negociar el disenso nos dará indicadores claros del grado de democratización de una sociedad específica. En el ámbito de la cultura esta apertura se cristaliza en los denominados derechos de participación (RAMOS CEBRIÁN, 2019). Así si entendemos como participación el derecho que tiene la ciudadanía a acceder a los lugares en los que se tomarán decisiones que afectarán a su vida, el correlato de la participación es la transparencia, es decir, el dere- cho a entender cómo se toman decisiones, se invierten los presupuestos y a la trazabilidad de proyectos e iniciativas acontecidas con apoyo público. Esto difiere sustancialmente de lo que denominamos cultura común, es decir el derecho ciudadano a crear y gestionar instituciones de carácter comunitario que pueden pero no siempre encuentran interlocución con lo público (ROWAN, 2016). Se nos abre un amplio espectro de formas de entender y practicar la participación.

Con esto vemos cómo se configura un interesante campo de tensiones dado que las instituciones públicas tienden a ser estáticas pese a tener que dialogar de forma constante con organizaciones ciudadanas activas que tienden a tensionar dichas instituciones. En este sentido la investigadora y activista Raquel Gutiérrez escribe que es necesario "entender la sociedad como mosaico dinámico de antagonismos superpuestos"(GUTIÉRREZ, 2017: 23). Lo social está cruzado por intereses, relaciones de poder y grupos que buscan influir y marcar decisiones institucionales. Grupos que diseñarán mecanismos para legitimar sus demandas e intereses. Las



Manifestación 15-M (15 Mayo 2012) | foto copsadmirer@yahoo.es 
a debate Hacia una nueva institucionalidad cultural. Modelos emergentes de gestión...

| coordina Jesús Carrillo Castillo

instituciones públicas reaccionan y conviven con estos antagonismos, en ocasiones asumiendo algunas de estas demandas, en ocasiones silenciando, ilegalizando o prohibiendo otros intereses. De esta manera, pese a parecer estático, el Estado siempre tiene un punto de contingencia, de inestabilidad. Su poder reside en su capacidad de asumir conflictos, integrarlos y normalizarlos. Legalizar y legitimar demandas sociales. Convocar procesos participativos o asumir demandas nacidas de proyectos autónomos.

Las instituciones públicas se transforman a medida que estos intereses cruzan y percuten sobre las mismas, son un reflejo de este cuerpo social en tensión y movimiento. Las instituciones legitiman ciertos grupos sociales, pero irremediablemente, tenderán a ignorar a otros. Por consiguiente las instituciones culturales darán legitimidad a ciertos intereses, prácticas o estéticas, e irremediablemente, ignorarán a otras. Las querellas sociales irán expresándose institucionalmente en forma de cambios de discurso, orientación o contenidos, pero por lo general, las estructuras institucionales no cambiarán, tenderán a perpetuarse. Para dar lugar a estas peticiones y necesidades sociales en los últimos años constatamos que se han multiplicado las consultas a la participación. Lamentablemente en muy pocos de estos casos estos espacios o planes eran de carácter vinculante. Se llamaba a participar pero no había forma técnica de hacerse cargo de las expresiones del malestar ciudadano. Se escuchaba pero no había forma prevista para ver cómo una demanda, queja o necesidad, era acogida y transformada en un cambio político o administrativo. Esto daba pie a lo que se viene llamando cherry picking, es decir, se escogen "aquellas iniciativas que se perciben como exitosas, que encajan en la misión política y los sistemas de gestión de la administración, y que no se consideran como una amenaza al orden espacial y social" (MOULAERT; SWYNGEDOUW; MARTINELLI et ál., 2010: 225).

Muchas de estas consultas o planes, si bien nacieron bienintencionados, chocaron con una realidad social imprevista; apenas hay organizaciones de carácter cul-

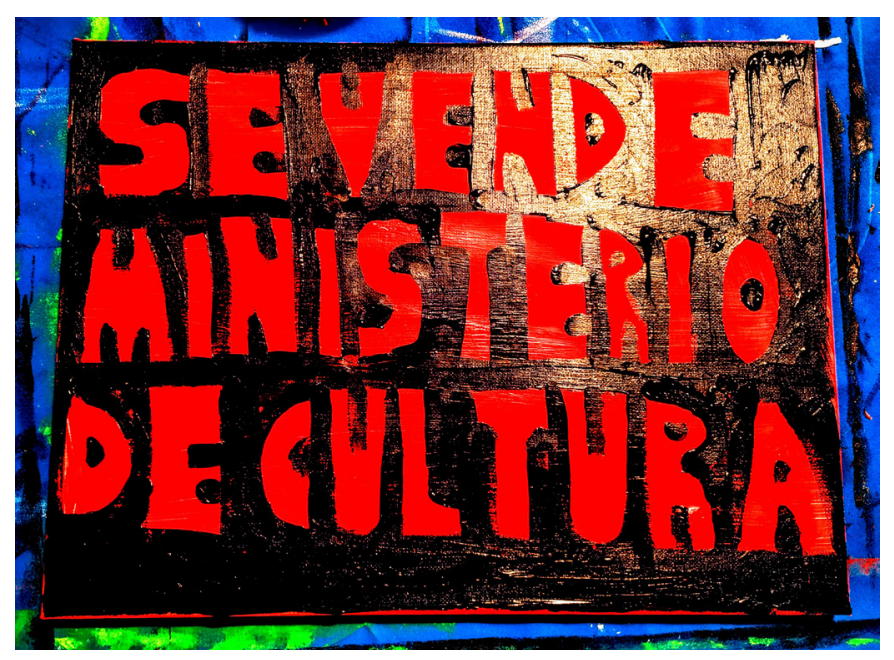

Foto Jaron Rowan

tural que no tengan un carácter sectorial capaces de expresar y acompañar la materialización de sus demandas. Si bien es verdad que existen ciertas organizaciones que representan los intereses de la patronal, las voces de las personas trabajadoras, ciudadanía y afectados por la cultura apenas tienen lugares de expresión. Así progresivamente, la participación pasó de buscar cómo cambiar estructuralmente las instituciones culturales, a convertirse en espacios para la opinión sobre contenidos de instituciones ya existentes. A la vez muchos de los patronatos de las grandes instituciones culturales apenas han cambiado; es decir, los lugares en los que se toman decisiones no se han visto afectados por los llamamientos a la participación. En este sentido, podríamos aventurar que la participación ha acontecido a un nivel superficial, sin alterar las estructuras de poder sobre las que se sustentan las instituciones culturales.

La tensión legalidad-legitimidad ha sido uno de los problemas políticos más importantes que se han encontrado los llamados gobiernos del cambio. Pese a la invitación a participar en la vida cultural de la ciudad, las administraciones se parapetaron tras requerimientos administrativos, técnicos, legales y jurídicos, para evitar gestionar el disenso y las expresiones de cultura común más antagonistas. Se han cerrado centros sociales y por lo general la interlocución con instituciones culturales de 
a debate Hacia una nueva institucionalidad cultural. Modelos emergentes de gestión...

| coordina Jesús Carrillo Castillo

base comunitaria ha sido complicada sino abiertamente conflictiva. Incluso los gobiernos del cambio han temido legitimar demandas culturales y sociales sobre las que tenían poco control. Esto nos debería llevar a preguntarnos: si no hay redistribución de poder ¿es la participación un simple ejercicio performativo? En lo que se refiere a las instituciones culturales todo apunta a que no han cambiado mucho durante este último ciclo político.

\section{BIBLIOGRAFÍA}

- BARBIERI, N. (2018) Políticas culturales en los ayuntamientos del cambio. ¿Hacia unas políticas públicas de lo común? Periférica Internacional. Revista para el análisis de la cultura y el territorio [en línea], n. ${ }^{\circ}$ 18, 2017 <https://revistas. uca.es/index.php/periferica/article/view/4199> [Consulta: 14/07/2020]

- GUTIERREZ, R. (2017) Horizontes comunitario-populares. Producción de los común más allá de las políticas estadocéntricas [en línea]. Madrid: Traficantes de Sueños, $2017<$ https://www.traficantes.net/sites/default/files/pdfs/ Horizontes\%20comunitario-populares_Traficantes\%20de\%20 Sue\%C3\%B1os.pdf> [Consulta: 14/07/2020]

- MOULAERT, F.; SWYNGEDOUW, E.; MARTINELLI, F.; GONZÁLEZ, S. (2010) Socially innovative projects, governance dynamics and urban change: Between state and self-organisation. En Can Neighbourhoods Save the City? Community Development and Social Innovation. London: Routledge, 2010

- RAMOS CEBRIÁN, S. (2019) Explorando los derechos de participación cultural y nuevas maneras de acceso a la cultura. Periférica Internacional. Revista para el análisis de la cultura y el territorio [en línea], n. ${ }^{\circ} 20,2019$, pp. 232-241 <https://revistas.uca.es/index.php/periferica/article/view/5593> [Consulta: 14/07/2020]

- ROSANVALLON, P. (2015) El buen gobierno. Buenos Aires: Manantial, 2015

- ROWAN, J. (2016) Cultura Libre de Estado [en línea]. Madrid: Traficantes de Sueños, $2016<$ https://www.traficantes. net/sites/default/files/pdfs/LEM7_cultura\%20libre\%20de\%20 Estado.pdf> [Consulta: 14/07/2020] 